\title{
DEVELOPMENTAL PALEOBIOLOGY OF THE VERTEBRATE SKELETON
}

\author{
MARTIN RÜCKLIN, ${ }^{1,2}$ PHILIP C. J. DONOGHUE, ${ }^{1}$ JOHN A. CUNNINGHAM, ${ }^{1}$ FEDERICA MARONE, ${ }^{3}$ AND \\ MARCO STAMPANONI ${ }^{3,4}$
}

${ }^{1}$ School of Earth Sciences, University of Bristol, Wills Memorial Building, Queen's Road, Bristol BS8 1RJ, UK, <M.Ruecklin@bristol.ac.uk>; $<$ phil.donoghue@bristol.ac.uk>; < john.cunningham@bristol.ac.uk >; ${ }^{2}$ Naturalis Biodiversity Center, Postbus 9517, 2300 RA Leiden, Netherlands, $<$ martin.rucklin@naturalis.nl>; ${ }^{3}$ Swiss Light Source, Paul Scherrer Institut, Villigen, Switzerland; <federica.marone@psi.ch>; $<$ marco.stampanoni@psi.ch>; and ${ }^{4}$ Institute for Biomedical Engineering, University and ETH Zürich, Zürich, Switzerland

\begin{abstract}
Studies of the development of organisms can reveal crucial information on homology of structures. Developmental data are not peculiar to living organisms, and they are routinely preserved in the mineralized tissues that comprise the vertebrate skeleton, allowing us to obtain direct insight into the developmental evolution of this most formative of vertebrate innovations. The pattern of developmental processes is recorded in fossils as successive stages inferred from the gross morphology of multiple specimens and, more reliably and routinely, through the ontogenetic stages of development seen in the skeletal histology of individuals. Traditional techniques are destructive and restricted to a 2-D plane with the third dimension inferred. Effective non-invasive methods of visualizing paleohistology to reconstruct developmental stages of the skeleton are necessary.

In a brief survey of paleohistological techniques we discuss the pros and cons of these methods. The use of tomographic methods to reconstruct development of organs is exemplified by the study of the placoderm dentition. Testing evidence for the presence of teeth in placoderms, the first jawed vertebrates, we compare the methods that have been used. These include inferring development from morphology, and using serial sectioning, microCT or synchrotron X-ray tomographic microscopy (SRXTM), to reconstruct growth stages and directions of growth. The ensuing developmental interpretations are biased by the methods and degree of inference. The most direct and reliable method is using SRXTM data to trace sclerochronology. The resulting developmental data can be used to resolve homology and test hypotheses on the origin of evolutionary novelties.
\end{abstract}

\section{INTRODUCTION}

$\mathrm{T}$ HE SKELETON has underpinned much of the evolutionary success that our vertebrate clade has enjoyed over the past half a billion years and, hence, there is a rich literature attempting to explain its evolutionary origin and assembly (e.g., see Donoghue and Aldridge, 2001). Indeed, the vertebrate skeleton was among the very earliest attempts to obtain a holistic understanding of the relationship between development and evolution - a nascent evolutionary developmental biologyin the nineteenth century (e.g., Williamson, 1849, 1851; Hertwig, 1874a, 1874b, 1876, 1879, 1882; Goodrich, 1909). Among living vertebrates, only the gnathostomes (living jawed vertebrates) possess a mineralized skeleton and since chondrichthyans (sharks, rays, and holocephalans) are the sister lineage to all other living jawed vertebrates (Osteichthyans), sharks have been the focus of studies that have attempted to understand vertebrate skeletal developmental evolution (e.g., Ørvig, 1951, 1968, 1977; Reif, 1976, 1978a, 1978b, 1980, 1982; Smith et al., 2012). However, even a cursory consideration of the fossil record reveals that chondrichthyans are a poor proxy for the earliest skeletonizing vertebrates, which are the extinct jawless 'ostracoderms' and jawed placoderms, the fossil remains of which record the gradual evolutionary assembly of the vertebrate skeleton (Donoghue and Sansom, 2002; Donoghue et al., 2006).

Developmental studies of extant taxa typically examine successive ontogenetic stages of developing organisms (Fig. 1; Cloutier, 2010; Rücklin et al., 2012; Sánchez-Villagra, 2012). This approach is difficult to apply to fossils as they are in most cases rare, often fragmentarily preserved and the timing between stages is uncertain. However, the vertebrate skeleton is one of the few organ systems that is routinely preserved in the fossil record, making it possible to obtain detailed morphological data of cells and tissues, as well as records of the development that can be interpreted through sclerochronology. Traditional histological methods used to reveal the sclerochronology of fossilized skeletal tissues are destructive, often laborious, and the resulting 2-D data can be difficult to interpret in three dimensions-leading to notorious controversies concerning the homology of skeletal tissues and structures.

Recently non-invasive tomography methods have been used to visualize tissue types and detailed structures like Sharpey's fibers in three dimensions (Rücklin et al., 2011, 2012; Cunningham et al., 2012; Sanchez et al., 2012, 2013; Giles et al., 2013). In particular, synchrotron tomographic methods provide the resolution and contrast required to interpret sclerochronology and reconstruct the development of the skeleton in 2-D (Curtin et al., 2012) or 3-D (Rücklin et al., 2011,2012 ). We review techniques that have been used to characterize the histology of fossil skeletal tissues and exemplify the importance of the newly gained evidence to test unresolved questions in vertebrate evolution and organ development. We summarize the pros and cons of the different techniques and demonstrate the potential of the new approaches.

\section{A BRIEF SURVEY OF PALEOHISTOLOGICAL TECHNIQUES}

The array of different techniques available to study histology and development in fossil vertebrates is briefly discussed summarizing advantages and limitations:

Light microscopy (LM).-Thin sections of specimens are cut, ground, and polished to a thickness that light can be transmitted through for studies using an optical microscope (see Downs and Donoghue, 2009, for detailed description of methodology). One section of the specimen is seen in high resolution enabling detailed paleohistological studies in two dimensions. 


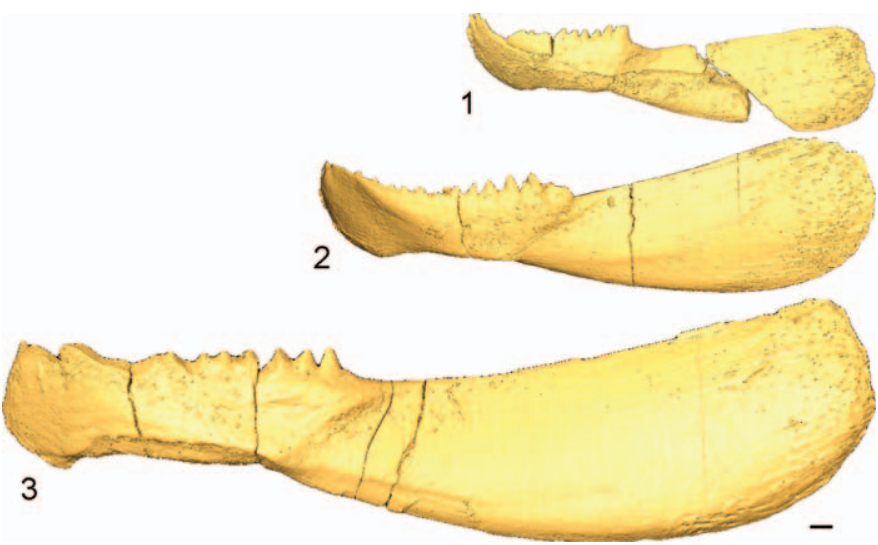

FIgURE 1 -Development inferred by arranging individual fossil lower jaws of Compagopiscis croucheri in a hypothesized ontogenetic sequence based on size (Rücklin et al., 2012). Volume rendering of microCT data: 1, WAM 91.4.3; 2, NHMUK PV P.50943; 3, NHMUK PV P.50948. Scale bar=1 mm.

Advantages to this method are the high resolution and the opportunity to analyze crystal orientation and mineral composition in a simple way. The necessary machinery (rock-saws, histological-saws, and polishing equipment), knowledge of how to produce a thin section and optical microscopes are standard in a classical geological or paleontological institution. Therefore thin sections are a cost-efficient and standard method in paleohistology and make it possible to identify histologic ontogenetic stages and developmental processes (e.g., Chinsamy, 2012; Klein and Sander, 2008; Padian and Lamm, 2013; Sander and Klein, 2005; Sander et al., 2006; Scheyer et al., 2010; Straehl et al., 2013).

The technique is limited by the fact that the exact direction of the section has to be decided from the gross morphology of the specimen. In specimens embedded in sediment and not exposed from the outside the cutting direction must be estimated and is often just a product of luck. A belated change of the sectional direction is impossible and as a result of the invasive method the original gross morphology of the specimen is destroyed irreversibly. The method is restricted to two dimensions and only a combination of several sections enables a coarse 3-D impression, restricted by the volumetric loss of the cutting device used. An example of material problems with the interpretation of 2-D sections is provided by the overestimation of amount of woven bone in long bones of sauropod dinosaurs (see Stein and Prondvai, 2013).

Scanning electron microscopy (SEM).-A surface is cut, ground and polished, and studied using a SEM (for a description of methodology see Downs and Donoghue, 2009; Giles et al., 2013). Scanning electron microscope images are produced using backscatter electron or secondary electron imaging resulting in very high resolution. Coating specimens before imaging (with carbon or gold) reduces or avoids charging of the specimen and enhances the quality of the image.

The advantage of the method is that it is a fast way of producing sections and visualizing them. Different mineralogies result in distinguishable grayscale levels and a general histological inventory plus details like hypermineralized structures and even very fine structures like crystallites are easily visible. Most geology and paleontology institutions have the required machinery, it is easily accessible, and knowledge of its use is standard.

Limitations are the destruction of the specimen and problems with estimating the cutting direction from the gross morphology of the specimen. The technique is limited to two dimensions and only a combination of several sections enables a coarse 3-D impression; resolution is limited by the volumetric loss associated with the cutting device used. Additionally, SEM is quite cost intensive due to the machinery involved and the coating method, where necessary.

Serial grinding or sectioning.- -Tomograms of serially ground and polished sections or thin sections of 3-D specimens are assembled as a tomographic data set and interpreted in a 3-D model (for examples and detailed description of methodology see Sollas, 1903; Sollas and Sollas, 1913; Stensiö, 1927; Ørvig, 1980; Sutton, 2008). This physical tomographic method was the pioneer technique in paleontological tomography first introduced by Sollas (1903). Traditionally, serially ground sections were captured as line drawings and transferred into layered wax cutouts, which are stacked and melted together forming a wax model as a basis for the study. Using a digital approach, captured images of the serial ground sections are aligned as tomographic dataset and reconstructed, e.g., using programs like Spiers, Avizo (Visualisation Science Group) or Mimics (Materialise).

The advantage of this tomographic method is that it makes it possible to visualize structures three dimensionally as physical or digital models. By using images or acetate peels of serial grinding sections, morphology is captured and it might be possible to trace lines of arrested growth (LAGs) in the 2-D cutting or grinding plane. Developmental stages and sequences can be inferred (Ørvig, 1980).

The invasive character of the method produces limitations: the fossil will be destroyed during analysis and therefore access to material is very limited due to scarcity of vertebrate fossils. Another limitation is produced by the direction of the grinding plane, which might vary and be far from perfect. Histology and LAGs can only be investigated in the grinding plane and it is not possible to trace structures in other dimensions.

MicroCT.-Using axial CT applied on small scales results in detailed tomograms with a voxel size of less than $5 \mu \mathrm{m}$, depending on the set-up. Volumetric data are studied using visualization software, e.g., Avizo (Visualisation Science Group) or Mimics (Materialise). Data are studied in the three planes and segmented, additional oblique planes are possible in every direction (see Sutton, 2008 for detailed description of methodology).

The advantage of this non-invasive method is the ability to study and label digital data in 3-D at relatively high resolution. MicroCT scanners are increasingly common at scientific or commercial institutions and capturing data is time efficient.

A limitation of the data quality is caused by the X-ray source; polychromatic light is used in microCT scanners and therefore beam-hardening artifacts can occur. Also, the energy of the X-rays may be too low to penetrate X-ray dense objects and slight differences of X-ray density are impossible to visualize. Using high resolution scanning, scan time increases dramatically. Generally the resolution achieved is insufficient to resolve LAGs and cellular and matrix details of fossilized skeletal tissues.

SRXTM.-Synchrotron Radiation X-ray Tomographic Microscopy (SRXTM) is an axial tomographic method, which makes use of a synchrotron, a particle accelerator, as a high-brilliance and coherent X-ray source. The brilliance allows monochromatization while preserving a high flux and the coherence is important for phase contrast and improvement in density resolution. The resulting tomographic data using this non-invasive method is of extraordinary resolution (voxel sizes in submicron scale) and contrast (Donoghue et al., 2006; Tafforeau et al., 2006). Volumetric data is studied and, due to the high resolution and signal-to-noise ratio, LAGs inside of the bones are traceable and models of successive growth stages can be reconstructed.

Advantages of the X-ray source and of monochromatic light include very fine resolution, no beam hardening, and few 
artifacts. Together these enable a dissection of successive growth stages that is only possible with synchrotron tomography. Optimized scan set-up and reconstruction routines enable a time-effective scanning procedure (Marone and Stampanoni, 2012).

The large magnification means that only a small field of view is possible, which can be increased using a $360^{\circ}$ scan with the rotation axis positioned at the border of the field of view. In this way it is possible to nearly double the width of the field of view offered by the objective while preserving spatial resolution. Additionally the cost-intensive experimental set-up and the scarcity of facilities limit the accessibility of this methodology. Also the size of data sets and therefore necessary hard- and software solutions are challenging. Finally, the necessary segmentation of the tomographic data is time consuming and can take several months for a single specimen.

TECHNIQUE COMPARISON

SRXTM has obvious advantages over the other methods we describe, but it has its own peculiar disadvantages. One of the main challenges is to achieve high-resolution data of specimens several centimeters in size with a large field of view. The method to increase the field of view using $360^{\circ}$ scans is also limited. Large data sets are produced requiring cost-intensive high-end hardware and software solutions, which are also limited in processable data-size. Large data sets must be downsampled, thereby losing resolution for segmentation. The higher source energies required for characterizing larger specimens, or $\mathrm{X}$-ray dense material, result in a small beam and an even smaller field of view, necessitating tiled-scanning of larger specimens. The decreasing signal-to-noise ratio in larger specimens is also problematic. The data collection itself is highly optimized and individual scans are very quick (Marone and Stampanoni, 2012), but the resulting data analysis can be extremely time-intensive. Therefore, other tomographic techniques like serial grinding are still used on specimens with high optical contrast. Improvements to this traditional method, such as digital image capturing and analyses using software applications, optimize what was once an extremely time-consuming procedure. A positive effect is also the smaller data size, which means the computational methods required are not as cost-intensive and time-consuming as those necessary for microCT or SRXTM data.

It is obvious from the survey that tomographic methods like serial grinding or X-ray based tomography are vastly superior to the sub-sampling approach of thin sectioning, or creating single ground planes for SEM analysis as structures can be followed in 3-D. While the resolution in optical microscopy of thin sections is superior to most methods, SRXTM and ptychographic tomography (Dierolf et al., 2010) are now rivaling this.

Finally, the availability of fossil material for analysis should be an important consideration in choosing among analytic methods. Where fossil material is abundant, destructive methods remain an efficient approach for simple research questions. And since these different approaches provide complementary insights into skeletal biology, a multi-method approach may be appropriate, because it provides a means of anchoring the resulting data into comparative descriptions in the literature. However, with the widespread availability of non-invasive $\mathrm{X}$ ray tomographic techniques, museum curators are increasingly reluctant to release material for destructive analysis.

\section{EXAMPLE}

As an example of the ability to reconstruct ontogeny in fossil vertebrates we use the reconstruction of the development of teeth and jaws in the earliest jawed vertebrates, the placoderms

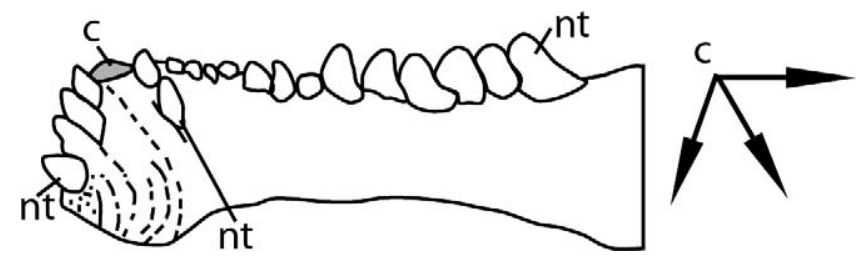

FIGURE 2-Lower jaw element (inferognathal) of Compagopiscis croucheri after Smith (2003, fig. 5b). Development inferred from morphology, main growth directions are in agreement with tomographic data, but no elements are distinguished and distal growth lines are completely contradictory to growth of the dental element reconstructed from tomographic data. Abbreviations: $\mathrm{nt}=$ hypothesized new tooth; $\mathrm{c}=$ hypothesized center of radiating tooth rows and primordial tooth position; arrows indicate growth direction of the three tooth rows.

(Janvier, 1996; Rücklin et al., 2012). The growth pattern must be reconstructed in order to test the hypotheses that structures on these jaws are 1) not teeth (Reif, 1982; Burrow, 2003; Young, 2003) but tubercles typical of the external dermal skeleton; 2) convergently evolved tooth-like structures (Johanson and Smith, 2003, 2005; Smith, 2003; Smith and Johanson, 2003); or 3) true teeth (Ørvig, 1980). To answer this question it is crucial to determine if the structures are growing on top of each other (appositional growth) like tubercles in the external dermal skeleton of many fishes, or as distinct structures in succession, polarized along a vector.

Given the extreme contradictory results of previous studies and the vitriolic debate with proponents defending their results we investigate this example. We ask what led to the different results and examine what kinds of methods were used and what artifacts and inherent errors they may have introduced.

For the first case, Reif (1982) followed published arguments based mainly on the gross morphology of placoderm jaws. The morphology was used to identify growth based on single specimens and single sections were interpreted. These were mainly based on very large specimens like Dunkleosteus (Heintz, 1932). No growth sequence was used and no sclerochronology studied, but his inference was untested and based on descriptions of single specimens.

In the second case, Johanson and Smith (2003, 2005), Smith (2003), and Smith and Johanson (2003) again inferred development from morphology arguing for a developmental pattern (Fig. 2). This was compared to other patterns and on the basis of the assumption that placoderms are monophyletic, the authors argued for a convergent evolution of teeth. No direct study of the development was undertaken. Due to the scarcity of material only few thin sections were used to identify tissue types and to argue for a similarity of tissues in crown group gnathostomes.

Finally, Ørvig (1980) used serial methods to achieve high resolution imaging of sections showing different elements (Fig. 3.1, 3.2; Ørvig, 1980, figs. 25, 26). The example demonstrates that the high resolution study of tissue types is possible using this technique (Ørvig, 1980, fig. 27). However, it also highlights problems in visualizing complete specimens and using interpretative drawings to identify different growth stages (Fig. 3.3; Ørvig, 1980, fig. 24). Due to the invasive nature of the method only one specimen of Plourdosteus canadensis was used for the study; wear on the jaw indicates that this specimen represents a late developmental stage. Developmental stages were not reconstructed by tracing LAGs, but inferred from the 2-D sections (Fig. 4.4; Ørvig, 1980, fig. 43). Early and late developmental stages are not preserved in the actual specimen and are hypothesized without any evidence. Also no reference is 

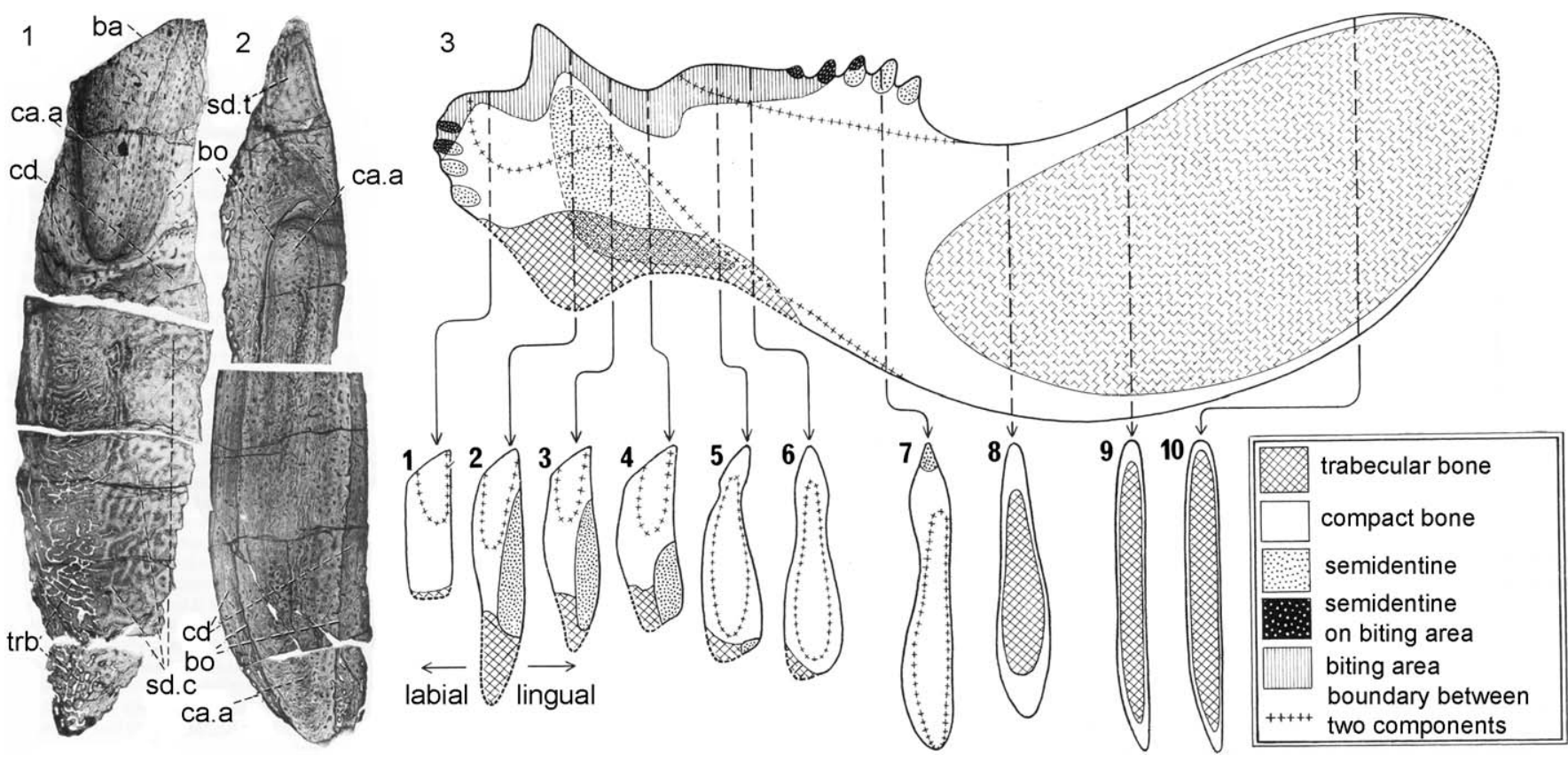

FIGURE 3 - Serial sectioning of lower jaws of Plourdosteus canadensis from Ørvig (1980): 1, vertical section through the distal part of the jaw corresponding to section 3 in 3; 2, vertical section through more proximal part of the jaw and teeth corresponding to section 7 in 3; 3, schematic illustration of the distribution of tissue types, elements, and sections inferred from the vertical serial sections through the jaws. The two different jaw ossifications are identified. Abbreviations: ba $=$ biting area; bo=boundary between jaw ossifications; ca.a=anterior part of axial component; $c d=d e n t a l$ component; sd.c=semidentine column; sd.t=semidentine tooth; trb=trabecular bone tissue.

given to other individual fossils that might represent different ontogenetic stages or might be used to infer a developmental sequence (Fig. 4.1-4.3, 4.5; Ørvig, 1980, figs. 40-42, 44). The LAGs are not reconstructed by following an actual growth line, but are idealized from the 2-D sections and the gross morphology. This demonstrates the limits of the method as crucial 3-D data and stages are missing and hypothesized. Notwithstanding his excellent optical microscopy data and detailed interpretation of tissue types, Ørvig's interpretation was limited by the 2-D data on which it was based.

In MicroCT scans the most prominent LAGs are visible (Fig. 5) and the different elements such as the bony shaft and the dental ossification are identifiable. Also lines of arrested growth between the teeth are visible as are structures like pulp cavities. The resolution of the scans is otherwise not sufficient to trace LAGs inside the dental ossification.

SRXTM scans reveal tissue types and cell types, like dentine and osteocyte cell spaces, with clarity (Fig. 6). Different elements like the bony shaft and the dental ossification are also visible (Fig. 6). These elements can be distinguished in 3-D and segmented for visualization (Fig. 7). LAGs are visible in the jaws of Compagopiscis croucheri as different gray scale values (Fig. 6), reflecting differentiated mineralization; they can be traced with great confidence. Successive growth stages are reconstructed volumetrically as 3-D models using visualization software (Figs. 7, 8). Directions of growth are reconstructed by the overlap of tissues separated by LAGs, allowing preceding and successive stages to be reconstructed with confidence (Fig. 8). Growth stages are displayed in the reconstructed succession demonstrating the developmental history of the individual specimen (Fig. 8). The crucial questions are answered using virtual paleontology. The structures in question are not growing on top of each other (not appositional) and are therefore not tubercles of the external dermal skeleton. In contrast the structures are distinct, separated by LAGs, in succession and polarized along three distinct vectors comparable to tooth families and can therefore be identified as teeth.

However, this conjecture of homology needs also to be corroborated by phylogenetic congruence to determine whether similarity is a consequence of convergence or common descent (Patterson, 1982; de Pinna, 1991). Therefore, we tested the homology by evaluating the evidence for phylogenetic continuity between teeth in arthrodires and crown gnathostomes (Rücklin et al., 2012). This test indicates that within the phylogenetic context of placoderm paraphyly (Brazeau, 2009; Davis et al., 2012) they can be identified as homologous to the teeth of crown gnathostomes.

SRXTM can also be used to distinguish qualitatively between different tissue types. In the example of Compagopiscis croucheri we demonstrate that teeth are composed of dentine and bone and exhibit a distinct pulp cavity that is in-filled centripetally as development proceeds.

To summarize and conclude this example, we suggest that the different results are biased by the degree of inference used in the applied method and argue that the most complete possible data set achieved through SRXTM might reconstruct development most accurately.

\section{OUTLOOK}

In order to reduce the time-consuming segmentation of paleontological specimens it might be possible to automate the process by applying algorithms similar to those used in skull stripping tools in medical magnetic resonance imaging (MRI). Increasing resolution of experiments and improvement of analytical hard- and software solutions will help to master an increasing quantity of data sets. Solutions are already becoming less cost-intensive and increasing numbers of synchrotron facilities will simplify access to the method and increase the number of experiments. 


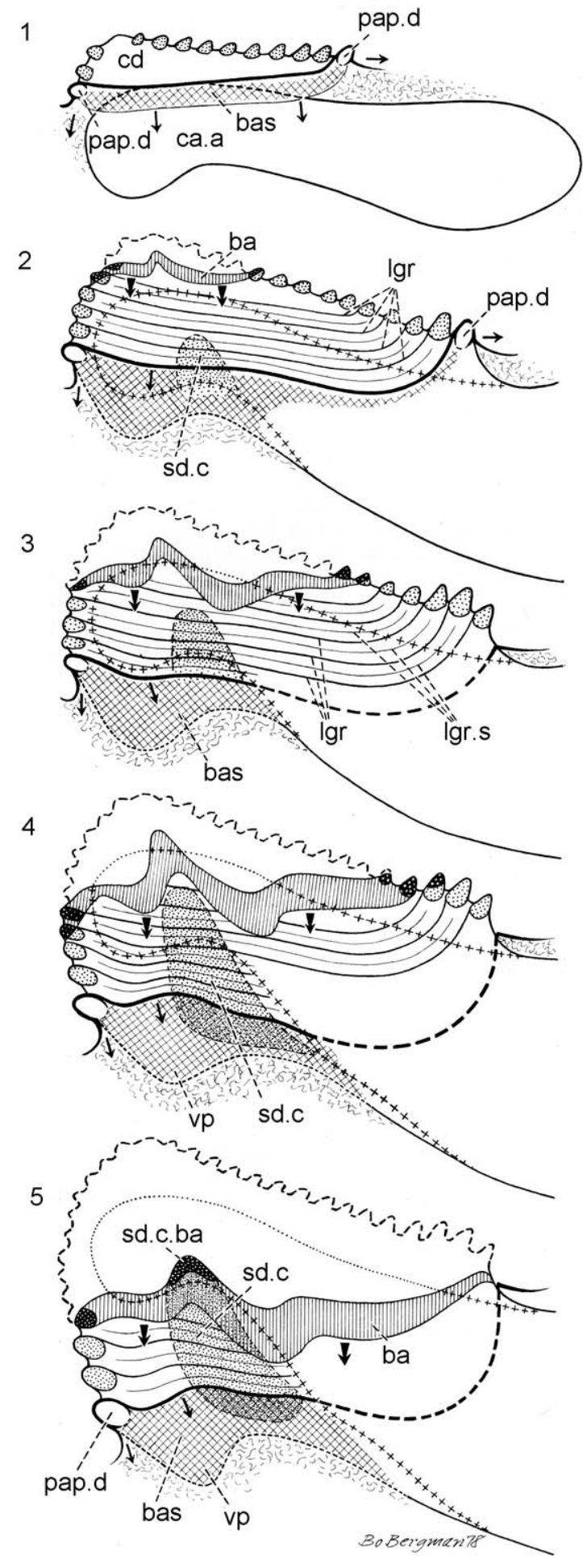

Figure 4-Inferred development of the lower jaw of Plourdosteus canadensis based on serial sectioning, from Ørvig (1980). Notice that developmental stages of the dental ossification are inferred, actual data from the specimen in Figure 3 are only available for the reconstruction in 4. 1, hypothetical early stage, no evidence is given for the cap like initial stage dental ossification with several teeth and two tooth-rows; 2 , hypothetical early wear-stage and growth of dental element with sequential addition of teeth in both tooth-rows, there is no evidence for the correlation of the growth line; 3 , hypothetical stage with almost complete wear of the initial dental ossification; lines of growth are idealized as rounded lines, not traced in three dimensions in the specimen; 4, developmental stage interpreted from the sections of the actual specimen; LAGs are not traced, just inferred from vertical sections and gross morphology, therefore no direct evidence is given for the ceased

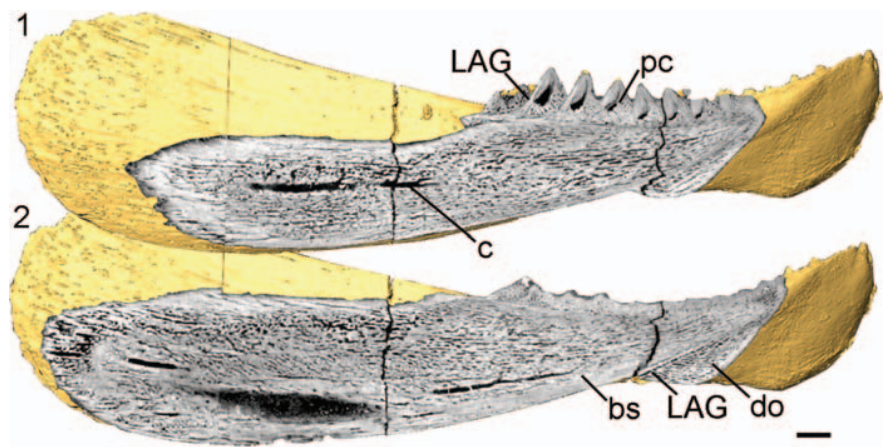

FigURE 5-Volume renderings of microCT data with longitudinal surface cuts of Compagopiscis croucheri (NHMUK P.50943): 1, lateral cut; 2, medial cut. Note the resolution that can be achieved and the anatomical structures that can be visualized using microCT, such as parts of the most prominent lines of arrested growth in between teeth or dental ossification and bony shaft. Abbreviations: bs $=$ bony shaft; $c=$ canal probably for the mandibular branch of the trigeminal nerve V; do=dental ossification; $\mathrm{LAG}=$ line of arrested growth; $\mathrm{pc}=$ pulp cavity. Scale bar $=1 \mathrm{~mm}$.

Three-dimensional printing can transform digital models into physical models that allow researchers to print the succession of developmental stages at every desired scale (Teshima et al., 2010). The size of originally microscopic structures can be increased in a 3-D print and studied in detail. In this way developmental sequences can be compared to one another, as well as to the embryology of extant taxa.

Growth and homology of growth patterns in different organ systems can be tested in the same way as our example, e.g., growth patterns of the dermal skeleton in stem group gnathostomes or the growth patterns of pectoral fins and limbs in stem and crown gnathostomes. All this is only possible if the histology is well preserved, which is fortunately often the case, and the bone is not completely remodeled and disguised through the activity of osteoclasts, which is often the case in the skeleton of crown-group gnathostomes.

The integration of deep time into developmental studies and the possibility to trace developmental processes with confidence in fossil taxa opens a new perspective for evolutionary developmental biology. In traditional histological studies two dimensions are examined and the third dimension is inferred. By creating virtual fossils it is possible to reconstruct the pattern of development of skeletal structures in an individual taxon; comparisons between taxa allow us to infer the evolutionary history of the underlying developmental processes. Hypotheses on developmental plasticity or heterochrony might be testable and developmental processes of the phenotype might be interpreted in light of gene regulatory networks and the genotype following a devo-evo approach (Wagner, 2000; Hall, 2003a, 2003b, 2012; Wagner et al., 2003).

\section{CONCLUSION}

Three-dimensional visualizations of complex structures in fossil vertebrates are only possible through the application of

addition in the proximal tooth row and continuous addition in the distal tooth row; 5, hypothetical late developmental stage, no evidence is given for the complete wear of the proximal tooth row in the specimen, nor is it illustrated in another individual that might be used to infer a sequence of development. Abbreviations: ba $=$ biting area; bas $=$ basal part; ca.a.=anterior part of axial component; $\mathrm{cd}=$ dental component; lgr=primary lines of growth; lgr.s=secondary lines of growth; pap.d=papillae of semidentine teeth under formation; sd.c $=$ column of osteo-semidentine; sd.c.ba $=$ osteosemidentine exposed on biting surface; $v p=$ ventral process. 


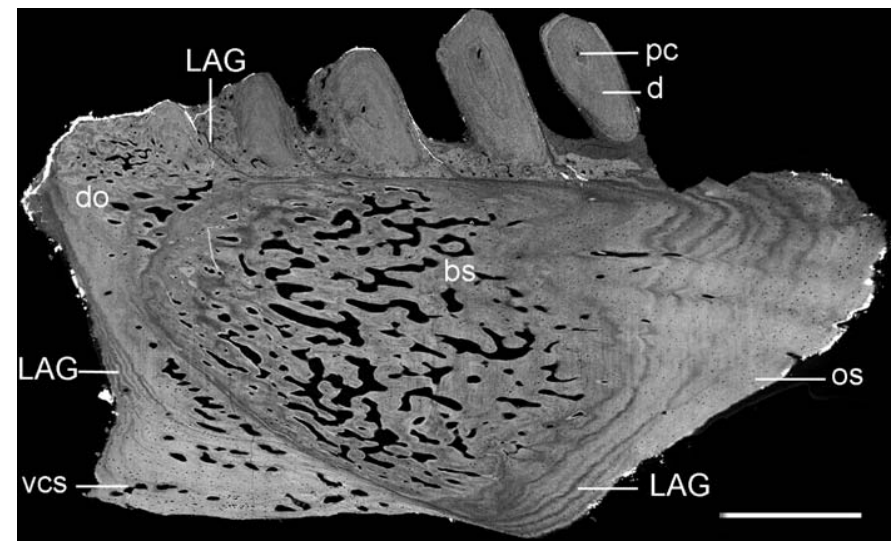

FigURE 6-Longitudinal section through SRXTM data showing the resolution achievable and visualization options of (i) anatomical structures like entire lines of arrested growth in between stages of the dental ossification and (ii) tissue types like dentine and vascular bone using SRXTM. Abbreviations: bs=bony shaft; $d=$ dentine; do=dental ossification; LAG $=$ line of arrested growth; os $=$ osteocyte space; $\mathrm{pc}=$ pulp cavity; vcs $=$ vascular canal space. Scale bar $=1 \mathrm{~mm}$.

virtual methods. Tracing lines of arrested growth (LAGs) is the most effective and precise methodology for reconstructing growth stages and, consequently, ontogenetic sequences. Two-D approaches are not reliable and are often impossible. In our example, testing the evolution of jaws and teeth in the arthrodiran placoderm Compagopiscis croucheri, we were able to trace LAGs inside the bone volume and reconstruct growth stages and growth directions. SRXTM is the only reliable method to obtain the resolution required to reconstruct development in skeletal structures of fossil vertebrates. As data collection and analysis are time and cost intensive this method is perhaps best applied to few representative model organisms and organ systems. Resulting developmental data are necessary to decipher the evolution of novel modules and the evolution of vertebrates.

\section{ACKNOWLEDGMENTS}

For suggestions and discussions MR is very grateful to $\mathrm{S}$. Lautenschlager (University of Bristol) and P. Janvier (MNHN, Paris). Help at the Swiss Light Source with the scanning process was provided by D. Murdock (University of Bristol), S. Giles, and A. Hetherington (both University of Oxford). Assistance at the microCT facility, roasting samples, was provided by K. RobsonBrown (University of Bristol). Advice on generating illustrations was given by S. Powell (University of Bristol). Access to material

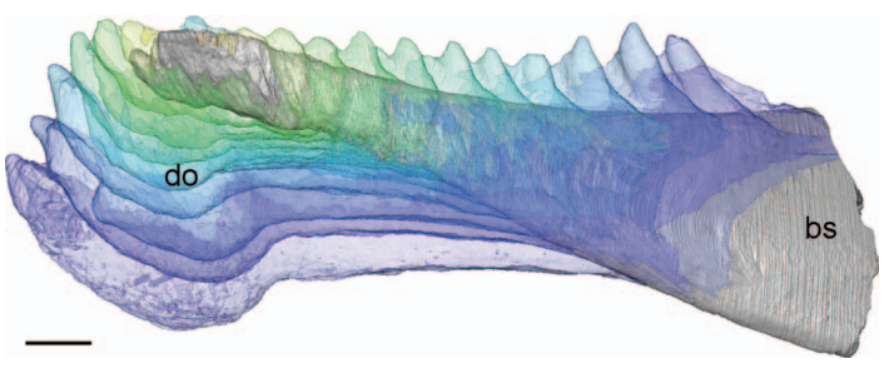

FIGURE 7-Segmented lines of arrested growth (LAGs) using SRXTM data of Compagopiscis croucheri (WAM 91.4.3). Model shows the reconstructed growth stages of the dental ossification (transparent colors) and the bony shaft (shaded gray). Abbreviations: $b s=$ bony shaft; do=dental ossification. Scale bar $=1 \mathrm{~mm}$.

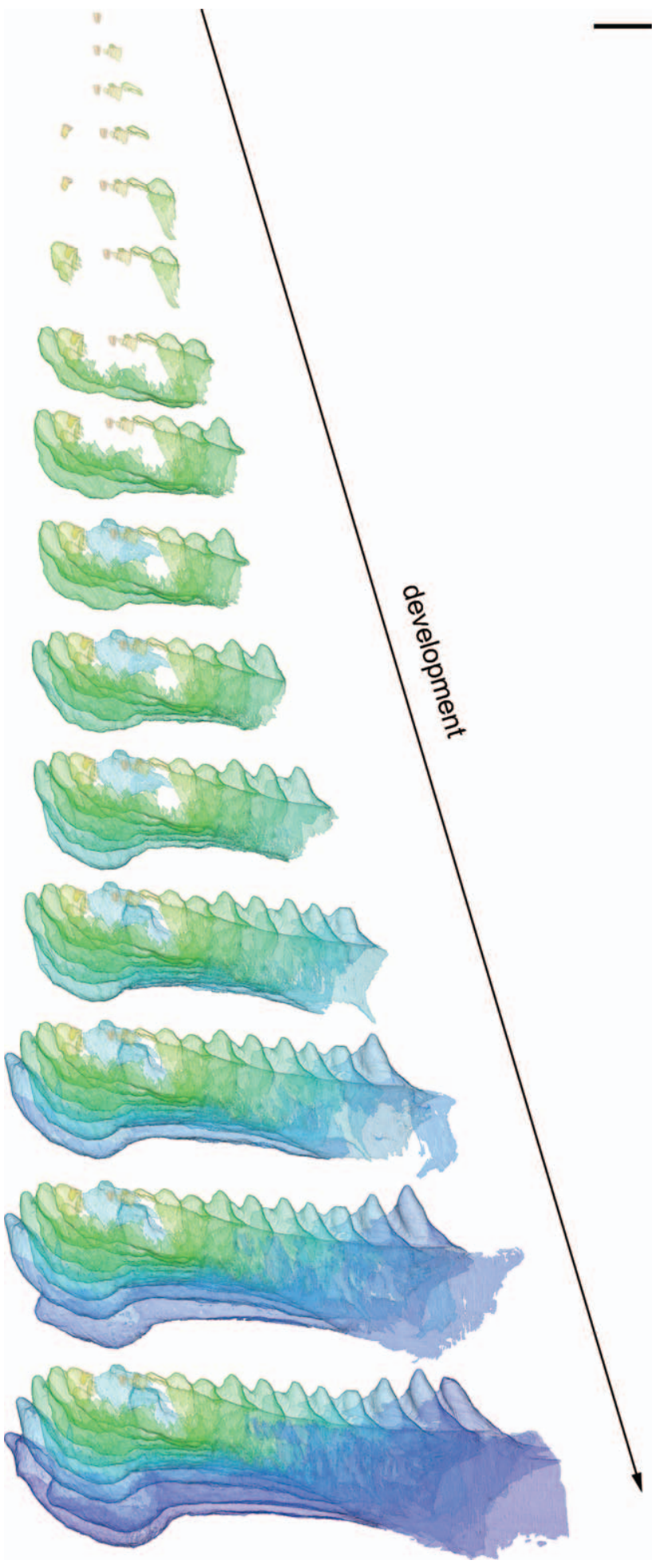

FIGURE 8-Virtual development of Compagopiscis croucheri (WAM 91.4.3) lower jaw. Segmented lines of arrested growth (LAGs) representing sclerochronology of the dental element. Scale bar $=1 \mathrm{~mm}$.

was provided by Z. Johanson (NHM, London) and K. Trinajstic (Curtin University, Perth Australia). Financial support of Framework Programme 7, Marie Curie Actions, EU was given to MR; Natural Environment Research Council, Standard Grant NE/G016623/1 to PCJD, and MR was supported by funds awarded to M. D. Brazeau from the European Research Council 
under the European Union's Seventh Framework Programme (FP/ 2007-2013) / ERC Grant Agreement number 311092.

\section{REFERENCES}

Brazeau, M. D. 2009. The braincase and jaws of a Devonian 'acanthodian' and modern gnathostome origins. Nature, 457:305-308.

Burrow, C. J. 2003. Comment on "Separate evolutionary origins of teeth from evidence in fossil jawed vertebrates." Science, 300:1661.

Chinsamy-Turan, A. 2012. Forerunners of Mammals: Radiation, Histology, Biology. Indiana University Press, Bloomington, U.S.A., 352 p.

Cloutier, R. 2010. The fossil record of fish ontogenies: Insights into developmental patterns and processes. Seminars in Cell and Developmental Biology, 21:400-413.

Cunningham, J. A., M. Rücklin, H. Blom, H. Botella, and P. C. J. Donoghue. 2012. Testing models of dental development in the earliest bony vertebrates, Andreolepis and Lophosteus. Biology Letters, 8:833-837.

Curtin A. J., A. A. Macdowell, E. G. Schaible, and V. L. Roth. 2012. Noninvasive histological comparison of bone growth patterns among fossi and extant neonatal elephantids using synchrotron radiation X-ray microtomography. Journal of Vertebrate Paleontology, 32:939-955.

Davis, S. P., J. A. Finarelli, and M. I. Coates. 2012. Acanthodes and sharklike conditions in the last common ancestor of modern gnathostomes. Nature, 486:247-250.

DE PINNA, M. C. C. 1991. Concepts and tests of homology in the cladistic paradigm. Cladistics, 7:415-394.

Dierolf, M., A. Menzel, P. Thibault, P. Schneider, C. M. Kewish, P. Wepf, O. Bunk, AND F. Pfeiffer. 2010. Ptychograpic X-ray computed tomography at the nanoscale. Nature, 467:436-439.

Donoghue, P. C. J. And R. J. Aldridge. 2001. Origin of a mineralised skeleton, p. 85-105. In P. E. Ahlberg (ed.), Major Events in Early Vertebrate Evolution: Palaeontology, Phylogeny, Genetics and Development. Taylor and Francis, London.

Donoghue, P. C. J., S. Bengtson, X.-P. Dong, N. J. Gostling, T. Huldtgren, J. A. Cunningham, C. Yin, Z. Yue, F. Peng, and M. Stampanoni. 2006. Synchrotron X-ray tomographic microscopy of fossil embryos. Nature, 442: 680-683.

Donoghue, P. C. J. And I. J. SAnsom. 2002. Origin and early evolution of vertebrate skeletonization. Microscopy Research and Technique, 59:352372.

Donoghue, P. C. J., I. J. SAnsom, And J. P. Downs. 2006. Early evolution of vertebrate skeletal tissues and cellular interactions, and the canalization of skeletal development. Journal of Experimental Zoology, Part B, Molecular and Developmental Evolution, 306B:278-294.

Downs, J. P. And P. C. J. Donoghue. 2009. Skeletal histology of Bothriolepis canadensis (Placodermi, Antiarchi) and evolution of the skeleton at the origin of jawed vertebrates. Journal of Morphology, 270:1364-1380.

Giles, S., M. Rücklin, And P. C. J. Donoghue. 2013. Histology of "placoderm" dermal skeletons: Implications for the nature of the ancestral gnathostome. Journal of Morphology, 274:627-644.

Goodrich, E. S. 1909. Vertebrata craniata. Volume IX, 518 p. In E. R. Lankester (ed.), Treatise on Zoology. Adam and Charles Black, London.

Hall, B. K. 2003a. Descent with modification: The unity underlying homology and homoplasy as seen through an analysis of development and evolution. Biological Reviews, 78:409-433.

Hall, B. K. 2003b. Evo-Devo: Evolutionary developmental mechanisms. The International Journal of Developmental Biology, 47:491-495.

Hall, B. K. 2012. Evolutionary developmental biology (Evo-Devo): Past, present, and future. Evolution: Education and Outreach, 5:184-193.

HeInTZ, A. 1932. The structure of Dinichthys: A contribution to our knowledge of the Arthrodira. In Archaic fishes. American Museum of Natural History, New York, 4:115-213.

Hertwig, O. 1874a. Ueber Bau und Entwickelung der Placoidschuppen und der Zähne der Selachier. Jenaische Zeitschrift für Naturwissenschaft, 8: 221-404.

Hertwig, O. 1874b. Ueber das Zahnsystem der Amphibien und seine Bedeutung für die Genese des Skelets der Mundhöhle. Eine vergleichend anatomische, entwickelungsgeschichtliche Untersuchung. Archiv für mikroskopische Anatomie, 11 supplement.

Hertwig, O. 1876. Ueber das Hautskelet der Fische. Morphologisches Jahrbuch, 2:328-395.

Hertwig, O. 1879. Ueber das Hautskelet der Fische. 2: Das Hautskelet der Ganoiden (Lepidosteus und Polypterus). Morphologisches Jahrbuch, 5:121.

Hertwig, O. 1882. Ueber das Hautskelet der Fische. 3: Das Hautskelet der Pediculati, der Discoboli, der Gattung Diana, der Centriscidae, einiger Gattungen aus der Familie der Triglidae und der Plectognathen. Morphologisches Jahrbuch, 7:1-42.

JANVIER, P. 1996. Early Vertebrates. Oxford Monographs on Geology and Geophysics 33. Clarendon Press, Oxford, 393 p.
Johanson, Z. And M. M. Smith. 2003. Placoderm fishes, pharyngeal denticles, and the vertebrate dentition. Journal of Morphology, 257:289-307.

Johanson, Z. AND M. M. SMith. 2005. Origin and evolution of gnathostome dentitions: A question of teeth and pharyngeal denticles in placoderms. Biological Reviews of the Cambridge Philosophical Society, 80:303-345.

Klein, N. And P. M. Sander. 2008. Ontogenetic stages in the long bone histology of sauropod dinosaurs. Paleobiology, 34:247-263.

Marone, F. AND M. Stampanoni. 2012. Regridding reconstruction algorithm for real time tomographic imaging. Journal of Synchrotron Radiation, 19:19.

ØRVIG, T. 1951. Histologic studies of ostracoderms, placoderms and fossil elasmobranchs 1 . The endoskeleton, with remarks on the hard tissues of lower vertebrates in general. Arkiv för Zoologi, 2:321-454.

ØRVIG, T. 1968. The dermal skeleton: general considerations, p. 374-397. In T. Ørvig (ed.), Current Problems of Lower Vertebrate Phylogeny. Almquist and Wiksell, Stockholm.

ØRVIG, T. 1977. A survey of odontodes ('dermal teeth') from developmental, structural, functional, and phyletic points of view, p. 53-75. In S. M Andrews, R. S. Miles, and A. D. Walker (eds.), Problems in Vertebrate Evolution: Linnean Society Symposium Series 4. Academic Press, London.

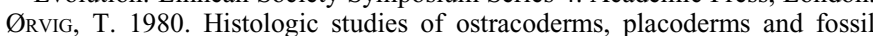
elasmobranchs 3. Structure and growth of gnathalia of certain arthrodires. Zoologica Scripta, 9:141-159.

Padian, K. AND E.-T. Lamm. 2013. Bone histology of fossil tetrapods. University of California Press, Berkeley, 298 p.

PAtTerson, C. 1982. Morphological characters and homology, p. 21-74. In K. A. Joysey and A. E. Friday (eds.), Problems of Phylogenetic Reconstruction. Systematics Association Special Volume 21. Academic Press, London.

REIF, W.-E. 1976. Morphogenesis, pattern formation and function of the dentition of Heterodontus (Selachii). Zoomorphologie, 83:1-47.

REIF, W.-E. 1978a. Shark dentitions: Morphogenetic processes and evolution. Neues Jahrbuch für Geologie und Paläontologie, Abhandlungen, 157:107-115.

REIF W.-E. 1978b. Types of morphogenesis of the dermal skeleton in fossil sharks. Paläontologische Zeitschrift, 52:110-128.

REIF W.-E. 1980. Development of dentition and dermal skeleton in embryonic Scyliorhinus canicula. Journal of Morphology, 166:275-288.

REIF, W.-E. 1982. Evolution of dermal skeleton and dentition in vertebrates: The odontode regulation theory. Evolutionary Biology, 15:287-368.

Rücklin, M., S. Giles, P. Janvier, And P. C. J. Donoghue. 2011. Teeth before jaws? Comparative analysis of the structure and development of the external and internal scales in the extinct jawless vertebrate Loganellia scotica. Evolution and Development, 13:523-532.

Rücklin, M., P. C. J. Donoghue, Z. Johanson, K. Trinajstic, F. Marone, and M. StampanONI. 2012. Development of teeth and jaws in the earliest jawed vertebrates. Nature, 491:748-751.

Sanchez, S., P. E. Ahlberg, K. Trinajstic, A. Mirone, and P. Tafforeau. 2012. Three-dimensional synchrotron virtual paleohistology: A new insight into the world of fossil bone microstructures. Microscopy and Microanalysis, 18:1095-1105.

Sanchez, S., V. Dupret, P. Tafforeau, K. M. Trinajstc, B. Ryll, P.-J. Gouttenoire, L. Wretman, L. Zylberberg, F. Peyrin, and P. E. Ahlberg. 2013. 3D microstructural architecture of muscle attachments in extant and fossil vertebrates revealed by synchrotron microtomography. PloS ONE, 8: e56992.

Sánchez-Villagra, M. R. 2012. Embryos in Deep Time. University of California Press, 265 p.

SANDER, P. M. AND N. KLEIN. 2005. Developmental plasticity in the life history of a prosauropod dinosaur. Science, 310:1800-1802.

Sander, P. M., O. Mateus, T. Laven, and N. Knötschke. 2006. Bone histology indicates insular dwarfism in a new Late Jurassic sauropod dinosaur. Nature, 441:739-741.

Scheyer, T. M., N. Klein, And P. M. SAnder. 2010. Developmental palaeontology of Reptilia as revealed by histological studies, p. 462-470. In M. R. Sánchez-Villagra (ed.), Developmental Vertebrate Palaeontology. Seminars in Cell and Developmental Biology, 21.

Sмith, M. M. 2003. Vertebrate dentitions at the origin of jaws: When and how pattern evolved. Evolution and Development, 5:394 413.

Smith, M. M. and Z. Johanson. 2003. Separate evolutionary origin of teeth from evidence in fossil jawed vertebrates. Science, 299:1235-1236.

Smith, M. M., Z. Johanson, C. Underwood, and T. G. H. Diekwisch. 2012. Pattern formation in development of chondrichthyan dentitions: a review of an evolutionary model. Historical Biology, 2012:1-16.

Sollas, W. J. 1903. A method for the investigation of fossils by serial sections. Philosophical Transactions of the Royal Society, B, 196:259-265.

Sollas, I. B. AND W. J. Sollas. 1913. A study of a Dicynodon by means of serial sections. Philosophical Transactions of the Royal Society, B, 204: 201-225.

Stensiö, E. A. 1927. The Downtonian and Devonian vertebrates of Spitsbergen. Part I. Family Cephalaspidae. Skrifter Svalbard Nordishavet $12,391 \mathrm{p}$. 
Stein, K. And E. Prondvai. 2013. Rethinking the nature of fibrolamellar bone: An integrative biological revision of sauropod plexiform bone formation. Biological Reviews, 89:24 47.

Straehl F. R., T. M. Scheyer, A. M. Forasiepi, R. D. MacPhee, and M. R. SÁNCHEZ-VILLAGRA. 2013. Evolutionary patterns of bone histology and bone compactness in xenarthran mammal long bones. PLoS ONE, 8: e69275.

Sutton, M. 2008. Tomographic techniques for the study of exceptionally preserved fossils. Proceedings of the Royal Society, B, 275:1587-1593.

Tafforeau, P., R. Boistel, E. Boller, A. Bravin, M. Brunet, Y. Chaimanee, P. Cloetens, M. Feist, J. Hoszowska, J.-J. Jaeger, R. F. Kay, V. Lazzari, L. Marivaux, A. Neil, C. Nemoz, X. Thibault, P. Vignaud, and S. Zabler. 2006. Applications of X-ray synchrotron microtomography for nondestructive 3D studies of paleontological specimens. Applied Physics A, Materials Science and Processing, 83:195-202.

Teshima, Y., A. Matsuoka, M. Fujiyoshi, Y. Ikegami, T. Keneko, S. Oouchi, Y. Watanabe, and K. Yamazawa. 2010. Enlarged skeleton models of plankton for tactile teaching. Lecture Notes in Computer Science, 6180: 523-526.
Wagner, G. P. 2000. What is the promise of developmental evolution? Part I: Why is developmental biology necessary to explain evolutionary innovations? Journal of Experimental Zoology, Molecular and Developmental Evolution, 288:95-98.

Wagner, G. P. And H. C. E. Larsson. 2003. What is the promise of developmental evolution? Part III: The crucible of developmental evolution. Journal of Experimental Zoology, 300B:1-4.

Williamson, W. C. 1849. On the microscopic structure of the scales and dermal teeth of some ganoid and placoid fish. Philosophical Transactions of the Royal Society of London, 139:435-475.

WiLliamson, W. C. 1851. Investigations into the structure and development of the scales and bones of fishes. Philosophical Transactions of the Royal Society of London, 141:643-702.

YounG, G. C. 2003. Did placoderm fish have teeth? Journal of Vertebrate Paleontology, 23:987-990.

Accepted 16 October 2013 